University of East London Institutional Repository: http://roar.uel.ac.uk

This paper is made available online in accordance with publisher policies. Please scroll down to view the document itself. Please refer to the repository record for this item and our policy information available from the repository home page for further information.

To see the final version of this paper please visit the publisher's website. Access to the published version may require a subscription.

Author(s): Tribe, Rachel.

Article title: Mental health of refugees and asylum-seekers Year of publication: 2002

Citation: Tribe, R. (2002) 'Mental health of refugees and asylum-seekers' Advances in Psychiatric Treatment 8 (4) 240-248

Link to published version: http://apt.rcpsych.org/cgi/reprint/8/4/240

DOI: (not stated)

ISSN: $1355-5146$

Publisher statement: http://bip.rcpsych.org/misc/ifora.dtl\#Copyright

Information on how to cite items within roar@uel:

http://www.uel.ac.uk/roar/openaccess.htm\#Citing 


\title{
Mental health of refugees and asylum-seekers
}

\author{
Rachel Tribe
}

This is the first in a series of papers on the mental health of marginal groups, including young refugees, homeless children and their families, elderly immigrant populations, prisoners and nurses.

Refugees are not a recent phenomenon. Since the time of the Roman Empire there have been many examples of people fleeing persecution and seeking refuge and protection in other countries. Refugees flee war, internal unrest and persecution by their own governments because of their ethnic origin or their political, religious or social activities. Estimates of the number of refugees and displaced people worldwide range from about 23 million to about 50 million, this latter figure including those who are not officially registered. It is perhaps pertinent to realise that this number is larger than the entire population of Australia and almost the same as the number of refugees resulting from the Second World War. Refugees represent a variety of cultures, races and nations from all over the world. Summerfield (2000) claims that nearly $1 \%$ of the people in the world are refugees or displaced persons resulting from about 40 current violent conflicts.

The terms asylum-seeker and refugee (see Box 1 for definitions) are frequently used in a negative and derogatory way, often associated with words such as bogus and scrounger. This type of language obscures the reality of who can be called refugees and why they seek sanctuary abroad. The status of those fleeing persecution is enshrined in international law, the United Nations Convention on Refugees, which resulted from a need to deal with the massive movements of people displaced by or fleeing the Second World War.
Countries that have signed the United Nations Convention on Refugees are obliged to consider the application of anyone who claims refugee status and grant that person refuge on the basis of the evidence. This is never an easy process for either party. Although not a subject for this article, it is inevitable that the quality of decision-making in different countries is variable and that some people, although genuinely fearing persecution in their own country, may be refused asylum.

The United Nations High Commission on Refugees (UNHCR) uses the words of Euripides, $431 \mathrm{BC}$, to describe the state of being a refugee or asylum-seeker: 'There is no greater sorrow on earth than the loss of one's native land.'

Normally the receiving or host country decides whether or not to grant an individual the right to refugee status, although in some countries the UNHCR may be asked to make this decision. In general, each individual case is decided on its merits. An asylum-seeker is someone who is requesting asylum or refuge and has asked to be given formal legal refugee status (Box 1). Without formal refugee status, asylum-seekers may find their access to services and legal rights curtailed. Asylumseekers also experience fear and uncertainty relating to whether their asylum applications will be rejected and they will be deported.

Internally displaced people residing in collapsing states are extremely vulnerable, usually possessing even fewer rights than refugees, particularly when human rights violations have occurred. For example, the recent conflicts in Kosovo and the genocide in Rwanda show the difficulties faced by international organisations in trying to protect civilians. The UNHCR tries to tackle such situations 'by encouraging states and other institutions to create

Rachel Tribe is a senior lecturer in psychology in the School of Psychology at the University of East London (Romford Road, London E15 4LZ, UK. E-mail: R.J.N.Tribe@uel.ac.uk). She has worked in a number of countries overseas. Her research interests include cross-cultural psychology, mental health and refugees in the UK and other countries, explanatory health beliefs and working with interpreters in mental health and trauma. 


\section{Box 1 Definitions}

\section{Refugees}

The 1951 United Nations Convention relating to the Status of Refugees states that a refugee is a person who, 'owing to a well-founded fear of being persecuted for reasons of race, religion, nationality, membership in a particular social group, or political opinion, is outside the country of his nationality, and is unable to or, owing to such fear, is unwilling to avail himself of the protection of that country' (UNHCR, 1951: Article $1 \mathrm{~A}(2))$.

Once recognised under the Convention, refugees have different rights to health, welfare and social services depending on the policies and resources of the host country concerned.

Asylum-seekers

Asylum-seekers may describe themselves as refugees, as this is what they hope to achieve, but they remain asylum-seekers while they are awaiting a decision on their application for refugee status.

Displaced persons

A displaced person is usually someone who has been forced to flee his or her home and community owing to civil war or persecution, often on political or religious grounds, but has been displaced within his or her country of origin, rather than to a different country.

Exceptional leave to remain (ELR)

This means that an individual has been granted permisssion to remain in the host country for a specific period of time. Someone granted ELR status is generally ascribed fewer rights than someone with full refugee status.

conditions which are conducive to the protection of human rights and the peaceful resolution of disputes' (UNHCR, 2002: p. 1). In pursuit of the same objective, the UNHCR actively 'seeks to consolidate the reintegration of returning refugees in their country of origin, thereby averting the recurrence of refugee-producing situations' (UNHCR, 2002: p. 1).

If further information is required about refugees, the UNHCR is probably the most useful agency. In addition, the International Committee of the Red Cross/Crescent runs a tracing service for people who have lost contact with family members through a war or on any other grounds (contact: The
British Red Cross, International Welfare Services, 9 Grosvenor Crescent, London SW1X 7EJ. Tel: 020 $77307674)$. They have also played an important role in providing services to refugees around the world and have acted as humanitarian intermediaries.

\section{Where do refugees go?}

Most refugees flee from developing countries across the border to other developing countries. Less than $17 \%$ of the world's refugees live in the developed West (personal communication, British Refugee Council, 2001). Many find themselves in refugee camps, which can be extremely hostile and frightening places, with shifting populations and little, if any, personal space. As a patient in an Asian country told me, 'We are the innocent victims in the big people's war, we all want it to stop ... What life is there for me and my children? We do not live in the refugee camp, we exist.'

A number of national and non-governmental health agencies around the world provide an impressive service, frequently with very limited resources, in an attempt to meet some of the physical and psychological health needs of people forced to reside in refugee camps.

However, at certain times in history various countries have sought out refugees in the same way that countries are currently actively seeking immigrants with particular skills, for example, people in India with computer skills are being sought by the USA and the UK. Countries to do this have included the USA, Canada and Australia. Thus, while refugees are often viewed as a burden, they may also prove to be a considerable asset.

Refugees have contributed significantly to knowledge around the world. Refugees in Britain include the inventor of the contraceptive pill and the first governor of the Bank of England. These individuals are among many others with prestigious achievements in the fields of medicine, law, music, art and architecture, to name but a few.

\section{Into exile}

Refugees differ from immigrants in that the latter have usually made a positive choice to change their country of residence and have been able to plan the move practically, psychologically and systematically over time. Refugees, on the other hand, usually have to flee for fear of their lives at short notice, often to unknown destinations. It is not a decision that is taken lightly, to risk losing everything your life has been built upon. Thus, to flee to a destination where 


\section{Box 2 Possible issues faced by refugees}

Causes

War

Human rights abuses

Persecution on grounds of politics, religion, gender or ethnicity

Resultant losses

Country

Culture

Family

Profession

Language

Friends

Plans for future

Issues in country of asylum

Multiple change

Psychological and practical adjustment

Uncertain future

Traumatic life events

Hardship

Racism

Stereotyping by host community

Unknown cultural traditions

an unknown future awaits can never be an easy decision and the factors listed in Box 2 are likely to be very stressful. Nevertheless, refugees may also feel immense relief that they have reached a safe haven and know that their lives are no longer under threat.

The period between applying for refugee status and a decision being made varies between countries from a number of hours to a number of years. This is an extremely stressful and uncertain time, when asylum-seekers are unable to make plans for the future and may be terrified of being returned to their country of origin. This may be a time when psychological well-being is extremely fragile.

Rumbaut (1991) noted that family loss is a predictor of psychological distress in the resettlement environment, and other researchers have claimed that differing views within the family group about the decision to flee were also negatively indicated. Families may suffer acute disruption and close families may be split. A frequent pattern is that one of the adults flees, with the possibility that his or her partner and children may follow later. Although families may also send unaccompanied children to safety as asylum-seekers in the West, this is usually done when parents fear that their child's life may be at risk if they remain in their country of origin.
Unaccompanied refugee children (those with no adult accompanying them into exile), make up between 2.5 and $5 \%$ of the refugee population (UNHCR, 1994). The immense loss of attachment figures and anyone or anything that is familiar may lead to these children requiring special provision (see Ressler et al, 1988).

\section{Exile-related stressors}

Several studies suggest that exile-related stressors may be as powerful as events prior to flight (Pernice \& Brook, 1996; Gorst-Unsworth \& Goldenberg, 1998). Among potential predisposing factors for psychological health problems in immigrants and refugees, the Canadian Task Force on Mental Health Issues (1998) lists: separation from family and community; an unwelcoming host community; prolonged or severe suffering prior to exile; being elderly or adolescent; lacking knowledge of the host language; and loss of socio-economic status.

The media has often focused on issues of economic migrancy rather than refugee issues. This has had the effect of further marginalising genuine asylumseekers and refugees. Responding clinically to the needs of some of those who become refugees may have implications and challenges for existing models of psychological intervention (Tribe, 1999a). The idea of talking to a psychiatrist, who is a stranger, about feelings may be an extremely alien and culturally incongruous concept, particularly given the associations with 'madness' and different cultural positioning around these issues. As discussed elsewhere (Tribe, 1999b), somatisation among refugee clients (patients) is frequently high; physical pain may be much more acceptable than psychological pain (Box 3).

\section{Box 3 Case example}

Pedro, a refugee from Latin America, once rushed into my office several minutes after our session had finished, in a highly anxious and aroused state. He told me he had bumped into a friend, Enriques, in the corridor. He begged me to tell Enriques that his appointment with me was in connection with an arm injury and to say nothing of any emotional dilemmas.

It appeared that it was fine to have physical health problems, but to have psychological ones was not acceptable as they were viewed as too stigmatising. 


\section{Implications for practice}

If an asylum-seeker or refugee approaches you for psychiatric help, one of the least helpful things you can do is contact the local embassy of his or her country of origin. Most refugees have fled their country of origin owing to persecution or atrocities, and for fear of their lives; they are usually terrified that their embassy, which is part of their government structure, may find them and take action against them or their families. It is impossible to assess the likelihood or not of this happening. Also, assuming that patients from the same country will have a lot in common and might, for example, be put in the same therapy group, is a high-risk strategy. When I was working at an agency offering health services to refugees based in London, there was a policy decision that two people of the same nationality would never be placed in the same therapeutic group. There will be refugees in the UK who share a nationality but are drawn from totally opposing political or religious groups. Given that refugees may have been forced to flee because somebody had spoken about their political, religious or ethnic views or background means that issues of trust may be problematic and require careful consideration. The refugees may also be extremely anxious about personal information getting into the wrong hands and being used against them or their family members in their country of origin (Box 4).

Psychiatrists may be asked to write and present legal reports for patients as evidence supporting their claim towards asylum/refugee status. This task does not always sit comfortably with the traditional

Box 4 Points to consider when treating asylum-seekers or refugees

Bear in mind that the patient may be extremely anxious about the security of personal information

Issues of trust may be problematic

Never contact the local embassy of their country of origin for information; instead, use organisations such as Human Rights Watch (33 Islington High Street, London N1 9LH. Tel: 0207713 1995; fax: 0207713 1800; http:/ / www.hrw.org) and Amnesty International (99-119 Rosebery Avenue, London EC1R 4RE. Tel: 0207814 6200)

It is usually unwise to put patients from the same country in the same therapeutic group role and may require careful consideration. It may mean a change of role for the psychiatrist or that the patient has to disclose experiences and give information at a pace that is seriously out of alignment with the psychiatric treatment. Refugees may also assume that you are familiar with the politics and human rights record of their country. This may mean that they do not immediately disclose episodes of human rights abuse or even of torture. They may assume that you will know from the place where they were imprisoned or their personal history what has happened to them.

People may present for help many years after becoming refugees, in the same way as those who have been through a traumatic experience. Miller (1999) cites McSharry \& Kinney's findings that in a randomised community sample of Cambodian refugees living in the USA, $43 \%$ were suffering from post-traumatic stress disorder (PTSD) 12-14 years after resettling in the USA.

People associated with a healing role may be community elders or family members, rather than psychiatrists, and such individuals may not be available to a refugee in exile. Refugee community organisations often play a vital role and frequently operate with very little funding. Miller (1999) has claimed that mental health needs of refugees in industrialised countries might be better served by complementing clinic-based treatments with a range of community-based initiatives, which may be viewed as more culturally acceptable. They may have the added benefit of providing opportunities for social and community support in a culturally familiar manner, and may be able to assist refugees to deal with the many exile-related stressors that exist, but are generally viewed as outside the remit of the psychiatrist. In addition, visiting a refugee community organisation may not carry the same connotations as visiting a mental health centre; furthermore, for many refugees the latter may not be within their repertoire of help-seeking behaviour anyway.

Refugees have experienced many losses, including perhaps a view of the world as a safe and benevolent place upon which they could have an impact. In various countries around the world psychiatrists have worked alongside community leaders, helping them to develop community-based interventions and to recognise when referral may be appropriate (Tribe \& de Silva, 1999). Culture may also be an extremely important variable in assisting people to maintain their equilibrium. The sense of familiarity and identity may be severely threatened for some refugees when they flee to a country so different from their own. In addition many refugee clients have learned that talking about their beliefs and experiences has led to their capture and perhaps organised violence 
and torture, therefore the idea of a talking cure may seem initially not only unlikely but frightening (Tribe, 1999a). This may mean that the process takes a rather different pace and may require consideration on the part of the psychiatrist.

\section{Working with unfamiliar languages and cultures}

Resources in the West are atypical, perhaps particularly in the area of mental health, which is frequently not viewed as a priority in a resourcelimited health environment. Simmonds et al (1983), in a review of refugee health care in developed nations, fail to mention mental health as an issue at all, which is a cause for possible concern. This is in addition to the fact that cultural interpretations about psychological distress, trauma and mental health may be viewed differently around the world, and this may require consideration by mental health practitioners.

The idea of evidence-based clinical practice may be relatively easy in the West, but it is not so easy with the very limited resources typically found in poorer countries. This issue may be further compounded by the fact that refugees are often resented by the host nation, which may feel less than inclined to put resources into refugee health and they may be attributed marginal or 'out-group' status.

A recently arrived asylum-seeker may not be fluent in spoken English and a psychiatrist may need to work with an interpreter or bicultural worker (see Box 5). The time at the beginning and end of the consultation can be used to develop a working alliance with the interpreter as well as to explain cultural factors and technical terminology. It may also be used to clarify procedural, organisational or ethical matters and to explain which interpreting model will be used.

The major models are the linguistic or literal interpretation; the psychotherapeutic model, which is more concerned with ensuring that the expressed emotions are conveyed by the interpreter to the psychiatrist; and the advocacy model, where the advocate interprets and advocates for the patient; or a combination of the three (see Tribe, 1999b; Tribe \& Raval, 2002). Explanatory health beliefs and constructions of psychological health or well-being for a refugee may bear little resemblance to those held by psychiatrists trained and practising in the West. Blackwell (1989: p. 2) writes:

'It is all too easy to repeat the colonising process by imposing a therapeutic ideology rooted in the culture of the host community, giving meaning to the survivors' experience in the language and symbols of that host community and its professionals, and failing to recognise the rich sources of meaning and symbolism available to the survivor from his or her own culture.'

The role and healing powers of different cultural practices and those of psychological interventions appears established. Rather than rejecting either, it would therefore appear most useful to try to isolate the positive factors within both frameworks. This may need addressing if the consultation is to be optimal for the patient (see Kleinman, 1980; Heigel, 1983; Fernando, 1995; de Silva, 1999).

\section{Refugees, trauma and the language of mental health}

The debate about whether most refugees require a psychiatrist and whether the language of mental health/illness is the most appropriate is a complicated issue and one that raises strong opinions. Practitioners in mental health services frequently report that few refugees present themselves (Bernier, 1992; Miller, 1999). There appear to be three major hypotheses

Box 5 Some issues to consider when a language and culture are not shared

Spend a few minutes with the interpreter before and after the session to clarify objectives, and review the meeting afterwards

Try to use the same interpreter for all the meetings with each individual or family; it is important to consider matching on age, gender and religious issues

Using an interpreter may mean that more time should be allocated for the meeting

Avoid specialist terminology

Use trained and experienced interpreters whenever possible; remember that they are part of the consultation and respect their contribution and different training

Always remain aware that you are interviewing someone from a different culture and who therefore may put different interpretations on events or feelings

Health beliefs about many aspects of psychiatry may be different across cultures

Remember that words may not translate exactly across languages 


\section{Box 6 Case example}

Mr A had been a young medical student in Africa and had suffered horribly at the hands of the authorities, who had tortured him for his political beliefs. He had a vision of what he thought would be a better world if his ideals for a more democratic system became established in his home country. Those in power did not agree. At this time $\mathrm{Mr} \mathrm{A}$ had viewed himself as a brave martyr or hero, standing up for his political views and what he saw as a better political system. His major coping strategy during this period appeared to relate to his membership of a tight-knit political group that provided a strong and rigid support network. The group believed absolutely in its own identity and purpose. Subsequently, he fled to Britain, as he feared for his life in his country of origin. He was referred to me, several years after his flight, by his general practitioner, who was concerned about his mental state.

My initial hypothesis was that his current distress was related to what I saw as his traumatic experiences in Africa and subsequent exile in Britain, but I was wrong. It was not related to the trauma of being tortured or his flight from a repressive regime, nor to the difficulties of living in exile. What was now causing him immense distress (he had active suicidal ideation) was that he had recently lost his political beliefs, which he now viewed merely as being an adolescent phase or rebellion. He was devastated to think that his suffering and the subsequent loss of his country, family, profession and culture had all been for what he now viewed as a developmental phase. His past political activities meant that he could not return to his country of origin as he was likely to be imprisoned and tortured. His torture and exile had felt bearable when he constructed them in terms of a political struggle and set of values. Now that he had lost his political beliefs, they felt unbearable and without any meaning.

that dominate the literature on refugees, trauma and mental health:

1 anyone who has been through the experiences of an asylum-seeker and has lost so much must be 'damaged' or traumatised;

2 people are very resilient and any reaction they have must be a normal one to abnormal events;

3 many refugees go through immensely trying times, which may be extremely distressing, and some may benefit from appropriate psychological help, which may not always be best presented as Western psychiatric help.

In reality, refugees are as diverse a group as any other and any of the above discourses may be true for a particular individual (see Box 6 for an example). It is vital that this diversity is considered when establishing resources or offering treatment or help to refugees. This is just as important as considering cultural differences and meanings. Whether the language of mental health and trauma is the most appropriate will continue to be debated in the literature. It is important to remember that becoming an asylum-seeker is always a major event in an individual's life. However, it is not the defining characteristic but rather a part of the whole. Some services for refugees have established themselves to deal almost exclusively with this part of refugees' lives. This may mean that the service they offer is skewed and may be over-reductionist. That is not to say that becoming a refugee is not a major life event and may not require specialist care. It is also important to recognise the immense powers of survival that people possess and to use these in our clinical work, as detailed elsewhere (Tribe, 1999a).

\section{Research into the mental health needs of refugees}

Refugees are a vulnerable group and a strict ethical code should govern research into this population. Leaning (2001) has recently suggested some guidelines on conducting such research.

The first widely published studies into refugee mental health were conducted after the Second World War and appeared to show a relationship between the severity of war experiences and psychiatric breakdown (Krupinski et al, 1973). The next major raft of studies was undertaken soon after the Vietnam war, when numbers of South-East Asian refugees fled to the West. These studies widened the focus of research from the earlier work and started to incorporate cultural variables and their role in the presentation of distress, as well as psychosocial factors relating to displacement. Much of the earlier work attempted to find a link between numbers and severity of traumatic events without due consideration of the meaning of these events to the individual. More recent studies have accommodated this important factor into the thinking. 


\section{Summary}

This paper has attempted to define how and why individuals are forced to become asylum-seekers, refugees or displaced people and to flee, often at very short notice, to a foreign country, to a refugee camp or a designated 'safe place' in their country of origin. Arrival in another country or region may not, in itself, give refugees peace of mind, as the intricacies of the asylum system and basic welfare and safety needs require immediate attention, as does living in a foreign country with a different culture, language and structure. In addition, individuals must come to terms with the immense losses frequently associated with flight and, perhaps most important, with loss of a belief in an imagined future.

\section{References}

Bernier, D. ( 1992) The Indochinese refugees: a perspective from various stress theories. Journal of Multicultural Social Work, 2, 15-29.

Blackwell, R. D. (1989) The Disruption and Reconstitution of Family, Network and Community Systems following Torture, Organised Violence and Exile. London: Medical Foundation.

Canadian Task Force on Mental Health Issues (1998) After the Door has been Opened: Mental Health Issues Affecting Immigrants and Refugees in Canada. Ottawa: Health and Welfare, Canada.

de Silva, P. (1999) Cultural aspects of post-traumatic stress disorder. In Post-Traumatic Stress Disorders, Concepts and Therapy (ed. W. Yule). Chichester: John Wiley \& Sons.

Fernando, S. (ed.) (1995) Mental Health in a Multi-Ethnic Society. London: Routledge.

Gorst-Unsworth, C. \& Goldenberg, E. (1998) Psychological sequelae of torture and organised violence suffered by refugees from Iraq. British Journal of Psychiatry, 172, 90-94.

Heigel, J. P. (1983) Collaboration with traditional healers: experience in refugee's mental care. International Journal of Mental Health, 12, 30-43.

Kleinman, A. (1980) Patients and Healers in the Context of Culture. Berkeley: University of California Press.

Krupinski, J., Stoller, A. \& Wallace, L. (1973) Psychiatric disorders in East European refugees now in Australia. Social Science and Medicine, 7, 31-49.

Leaning, J. (2001) Ethics of research in refugee populations. Lancet, 357, 1432

Miller, K. (1999) Rethinking a familiar model: psychotherapy and the mental health of refugees. Journal of Contemporary Psychotherapy, 29, 283-306.

Pernice, R. \& Brook, J. (1996) Refugees' and immigrants' mental health: association of demographic and post-migration factors. Journal of Social Psychology, 136, 511-519.

Ressler, E. M., Boothby, N. \& Steinbock, D. J. (1988) Unaccompanied Children. New York: Oxford University Press.

Rumbaut, R. G. (1991) The agony of exile: a study of the migration and adaptation of Indochinese refugee adults and children. In Refugee Children: Theory, Research, and services (eds F. L. Ahearn \& J. L. Athey), pp. 59-91. Maryland, MD: John Hopkins University Press.

Simmonds, S., Vaughan, P. \& Gunn, S. W. (1983) Refugee Community Health Care. Oxford: Oxford University Press.

Summerfield, D. (2000) War and mental health: a brief overview. BMJ, 321, 3323-3325.
Tribe, R. (1999a) Therapeutic work with refugees living in exile: observations on clinical practice. Counselling Psychology Quarterly, 12, 233-242.

- (1999b) Bridging the gap or damming the flow? Using interpreters/bicultural workers when working with refugee clients, many of whom have been tortured. British Journal of Medical Psychology, 72, 567-576.

- \& Raval, H. (2002) Undertaking Mental Health Work using Interpreters. London: Routledge (in press).

— \& de Silva, P. (1999) Psychological intervention with displaced widows in Sri Lanka. International Review of Psychiatry, 11, 186-192.

UNHCR (1951) The 1951 Refugee Convention. Geneva: UNHCR. - (1994) Refugee Children: Guidelines on Protection and Care. Geneva: UNHCR.

- (2002) UNHCR Mission Statement. Geneva: UNHCR.

\section{Multiple choice questions}

1. When a psychiatrist needs to use an interpreter, best practice suggests that:

a the interpreter will just follow the psychiatrist's lead as the consultation progresses

$\mathrm{b}$ it is important to spend a few minutes with the interpreter before and after the session reviewing issues pertinent to the consultation

c it is necessary to discuss every aspect of the case with the interpreter

$\mathrm{d}$ it is helpful to use the same interpreter for all the meetings whenever possible

e the interpreter should not be allowed to speak other than to interpret what is said.

2. Which of the following statements are true:

a it is important to remain aware that you are interviewing someone from a different culture who may put different interpretations on events or feelings

$\mathrm{b}$ issues of trust and confidentiality may require additional consideration

c refugees are a very recent phenomenon

$\mathrm{d}$ it is always a good idea to place asylum-seekers from the same country in a therapy group together

e most refugees flee to developed nations.

3. Studies suggest that exile-related stressors may be:

a more powerful than events prior to exile

b less powerful than events prior to exile

c equally as powerful as events prior to flight

d irrelevant

e any relationship is as yet unknown.

4. The correct legal definition of a refugee is:

a anyone who has applied for asylum

b anyone who is thinking of applying for asylum

c a and b above

d someone who has been granted exceptional leave to remain (ELR) status 
e someone who has been granted refugee status by the host government.

5. Unaccompanied refugee children (those with no adult accompanying them into exile) make up:
a $2.5-5 \%$ of the refugee population
b $23 \%$ of the refugee population
c $0.5 \%$ of the refugee population
d $25 \%$ of the refugee population
e $52 \%$ of the refugee population.

\begin{tabular}{llllllllll|} 
MCQ answers & & & & & & \\
1 & & 2 & & 3 & & 4 & & 5 & \\
a & F & a & T & a & F & a & F & a & T \\
b & T & b & T & b & F & b & F & b & F \\
c & F & c & F & c & T & c & F & c & F \\
d & T & d & F & d & F & d & F & d & F \\
e & F & e & F & e & F & e & T & e & F
\end{tabular}

\section{Commentary}

\section{Derek Summerfield}

What prior assumptions might a psychiatrist bring into the room when the patient is an asylum-seeker? First, as a member of the public he or she is likely to have a view on asylum-seeking as a sociological phenomenon - up to 5 million have sought asylum in Western Europe in the past decade - and on how 'deserving' the average case is. After all, two adversarially opposed constructions of asylumseeking have predominated. Governments, and the conservative social sectors, have stressed the prevalence of 'bogus' applications by people who are essentially economic migrants, portraying them as wily, determined and tough rather than as having suffered. On the other side are the agencies and interests who support asylum-seekers, and the liberal and radical social sectors. They portray asylum-seekers as people who had no choice but to run from their countries, innocent of any thought but to escape further persecution and the risk of death. This portrayal invokes the image of suffering and vulnerability rather than resilience and agency. The reality is the muddied, uneven terrain that lies between these two entrenched positions. Many asylum-seekers do not have stories that easily fit the definition of a political refugee in the 1951 United Nations Convention. Even those with the clearest-cut cases - such as those with a credible history of torture - usually cannot prove it; few are vulnerable in any medically attestable sense and, however much they have suffered, they continue to make choices and actively engage with their situations. All asylum-seekers are looking for a better life for themselves and their children.

Behind all this stands the implacably widening gulf between the socio-economic fortunes of the Western world and the rest of the planet. In most of Africa, South America and Asia, living standards, including indices such as access to schools and public health as well as jobs, have fallen strikingly in the past 20 years in relation to what had been achieved by the 1960s and 1970s. Structurally inequitable societies whose elites are prepared to use force to defend what they have (often with Western collusion) are as much the norm as the exception. The Western-led economic order dictates the terms of trade to third world nations, with the poorest not being the priority. The developmentalist ideal that the fortunes of the world's poor would gradually converge on those of the better-off has died. The Western political order is focused on what has been called 'the management of difference', an ominous phrase. One element of this is raising the

Derek Summerfield is an honorary senior lecturer in psychiatry at the Institute of Psychiatry (De Crespigny Park, Denmark Hill, London SE5 8AF, UK), a research associate at the Refugee Studies Centre, University of Oxford, and a former consultant to Oxfam. 
height of the fences around the wealthy Western societies to keep unwanted outsiders out (Duffield, 1996). The asylum-seeker is the beggar at the rich man's gate.

The other background factor that can influence how a psychiatrist manages an asylum-seeker or refugee is his or her assumptions about the personal legacy of, say, experiences of atrocity or torture. Do these self-evidently make victims candidates for a diagnosis of post-traumatic stress disorder (PTSD) and a psychological intervention? Elsewhere, I have critiqued the problems associated with the application of PTSD on a supposedly universalistic basis to nonWestern patients - and even to Western ones (Summerfield,1999, 2001). PTSD has become a catchall diagnosis and signifier, yet its criteria are frequently not what refugees consider significant about their predicament. Even when cross-cultural factors are not present, PTSD has low specificity, distinguishing poorly between the physiology of normal distress and the physiology of pathological distress. A finding that $43 \%$ of Cambodian refugees had PTSD 12 years after settling in the USA (cited by Tribe, 2002, this issue) says little about how they had fared and what they most needed. During the 1990s, I saw over 800 asylum-seekers and refugees with a history of exposure to political persecution and torture, referred to me for psychiatric assessment: remarkably few had significant psychopathology.

As Tribe notes, presentations in a physical idiom, in the absence of diagnosable organic disease, are common in general practitioner surgeries. To label all this 'psychosomatic' is too crude: somatic idioms of distress are located in multiple systems of meaning serving diverse personal and sociocultural functions (Kirmayer \& Young, 1998). Asylumseekers may be as interested in advocacy as in treatment, seeing the doctor (as British patients may do too) as a gatekeeper to scarce social resources such as public housing.

Those with pre-flight contact with health services for psychological reasons seem overrepresented among psychiatric referrals in the UK. Properly resourced and supervised interpreter services are needed. We need more sophistication in psychiatric encounters across cultural boundaries and an awareness that the degree of 'fit' is likely to be poor between National Health Service mental health services and presentations by asylum-seekers from cultures where Western psychiatry and the detached introspection of talk therapy are alien. 'Culturally sensitive' psychiatry can mean using an interpreter not to elicit the model of illness the patient holds, but rather to garner answers that permit pigeonholing in pre-set biomedical categories (Watters, 2001). DSM-IV (American Psychiatric Association, 1994) and ICD-10 (World Health Organization,
1992) are not, as some imagine, atheoretical and purely descriptive nosologies. They are Western cultural documents, carrying particular ontological notions of what constitutes a real disorder; epistemological ideas about what counts as scientific evidence; and methodological ideas as to how research should be conducted (Mezzich et al, 1999). PTSD is a Western culture-bound syndrome, but I would argue that all of psychiatry is culture-bound: even presentations by patients with organic mental disorders are shaped by local points of view and lifeworlds.

One danger of overemphasising the medical approach to refugees from war or atrocity is that still-evolving concerns and understandings are reduced to a unitary concept, 'trauma', neglecting the role of social factors in exile. The GorstUnsworth \& Goldenberg (1998) paper cited by tribe, found that depressed mood in Iraqi asylum-seekers in London was more closely related to the presence or absence of current social supports than to a history of torture. Eastmond (1998) found that survivors of Bosnian concentration camps living in Sweden did better when offered work-training than when offered psychological services. At 1 year the majority of the second group were on indefinite sick leave. The one surely indisputable fact in the literature of involuntary migration is that people do well, or not, as a function of their capacity to rebuild social capital and meaningful ways of life. Work is central to this.

\section{References}

American Psychiatric Association (1994) Diagnostic and Statistical Manual of Mental Disorders (4th edn) (DSM-IV). Washington, DC: APA.

Duffield, M. (1996) The symphony of the damned: racial discourse, complex political emergencies and humanitarian aid. Disasters, 20, 173-193.

Eastmond, M. (1998) Nationalist discourses and the construction of difference: Bosnian Muslim refugees in Sweden. Journal of Refugee Studies, 11, 161-181.

Gorst-Unsworth, C. \& Goldenberg, E. (1998) Psychological sequelae of torture and organised violence suffered by refugees from Iraq. British Journal of Psychiatry, 172, 90-94.

Kirmayer, L. \& Young, A. (1998) Culture and somatization: clinical, epidemiological and ethnographic perspectives. Psychosomatic Medicine, 60, 420-429.

Mezzich, J., Kirmayer, L., Kleinman, A., et al (1999) The place of culture in DSM-IV. Journal of Nervous and Mental Disease, 187, 457-464.

Summerfield, D. (1999) A critique of seven assumptions behind psychological trauma programmes in war-affected areas. Social Science and Medicine, 48, 1449-1462.

- (2001) The invention of post-traumatic stress disorder and the social usefulness of a psychiatric category. $B M J$ 322, 95-98.

Tribe, R. (2002) Mental health of refugees and asylumseekers. Advances in Psychiatric Treatment, 8, 240-247.

Watters, C. (2001) Emerging paradigms in the mental health care of refugees. Social Science and Medicine, 52, 1709-1718.

World Health Organization (1992) The ICD-10 Classification of Mental and Behavioural Disorders. Geneva: WHO. 